\title{
Jogos eletrônicos e a busca da excitação
}

\author{
Leoncio José de Almeida Reis* \\ Fernando Renato Cavichiolli**
}

\begin{abstract}
Resumo: No ramo do entretenimento, a indústria dos jogos eletrônicos foi a que mais cresceu na última década, tendo atraído atenção de pesquisadores de diversas áreas, dentre elas a Educação Física. Por que os jogos eletrônicos têm despertado tamanho interesse como opção de lazer para crianças, jovens e adultos? Neste estudo pretendemos discutir sobre uma possível forma de interpretar, a partir da teoria de Norbert Elias e Eric Dunning, os jogos eletrônicos como opção de lazer, utilizando como ferramenta auxiliar questionários respondidos por indivíduos que jogam videogames. A intenção é tecer algumas reflexões que colaborem para o entendimento desta prática lúdica.
\end{abstract}

Palavras-chave: Jogos de vídeo. Atividades de lazer. Emoções. Indústria eletrônica.

\section{INTRODUÇÃO}

Ao visitar um amigo pudemos observar uma situação inusitada. Enquanto o pai, sentado na poltrona, jogava videogame e, de vez em quando, beliscava um amendoim salgado e bicava uma cerveja, seu filho, uma criança que recém completara oito anos, brincava no estacionamento do prédio onde moravam. À primeira vista, os dois participavam de atividades totalmente distintas, mas logo, a partir de observações mais detalhadas, foi possível encontrar semelhanças esclarecedoras. Da janela era possível ver que o filho estava envolvido em uma brincadeira denominada pelos próprios meninos como "polícia pega ladrão". Ali do alto, era visível a movimentação silenciosa das crianças. Elas se esgueiravam entres os carros, escondiam-se atrás dos pilares, espiavam pelas frestas, se comunicavam com gestos,

\footnotetext{
Aluno do programa de pós-graduação (Mestrado em Educação Física) do Curso de Licenciatura em Educação Física. Universidade Federal do Paraná, Curitiba, PR. Brasil. E-mail: leojar_edf@yahoo.com.br

" Doutor em Educação. Professor do Departamento de Educação Física. Curso de Licenciatura em Educação Física. Universidade Federal do Paraná, Curitiba, PR. Brasil. E-mail: cavicca@ufpr.br
} 
enfim, executavam movimentos cautelosos e precisos, pois desejavam surpreender o adversário e também, é claro, sobreviver no jogo. Era perceptível a emoção que elas sentiam naquela brincadeira. As expressões faciais e motoras e os movimentos corporais por elas executados indicavam precisamente as emoções que elas sentiam em cada situação. Era possível perceber nelas a hesitação e a ansiedade antes de uma corrida até outro ponto mais seguro, a alegria de salvar um companheiro, a decepção e a tristeza de ser eliminado do jogo, o medo, a insegurança, etc.

O pai, apesar de estar envolvido em uma atividade cujo estilo e forma divergem totalmente da atividade descrita acima e que se concretiza num espaço físico também diferente, se divertia com um jogo eletrônico que apresentava mecanismos muito semelhantes ao jogo que o filho paralelamente participava. Era um jogo de videogame que simulava uma visão em primeira pessoa, ${ }^{1}$ no qual o jogador controlava um policial e deveria invadir um cassino protegido por bandidos. Nele, o jogador deveria ter, além de boa pontaria, muita cautela para não ser surpreendido pelos inimigos. Assim, em vários momentos, também era possível perceber, através da movimentação do personagem dentro do jogo, o mesmo padrão de cautela e precaução observado nas crianças que brincavam lá embaixo. A personagem era guiada lentamente pelos corredores, espiava do canto da parede e por debaixo das portas, ou às vezes saía correndo em busca de uma posição mais estratégica. O próprio jogador demonstrava claramente, através de expressões faciais e movimentos bruscos das mãos e dos braços, sinais emotivos, principalmente quando era pego desprevenido ou quando percebia que estava sendo alvejado pelos inimigos. Era transparente a tensão sentida pelo jogador em determinados momentos, muito semelhante ao que acontecia com as crianças. Essa tensão era mais facilmente perceptível quando se observava as atitudes representadas no jogo aliadas às expressões reais do jogador.

Todavia, não nos cabe aqui procurar elementos que possam igualar ou diferenciar estas duas atividades de lazer, ou que possam

${ }^{1}$ Nesses estilos de jogos eletrônicos a imagem simula a visão do personagem que é controlado no jogo. É como se aquilo que o personagem está vendo no jogo fosse representado na tela. Ou seja, a imagem reproduzida seria aquela captada pelos olhos do personagem.

Movimento, Porto Alegre, v. 14, n. 03, p. 163-183, setembro/dezembro de 2008. 
apontar vantagens e desvantagens de uma em relação a outra, a não ser o fato de que ambas as atividades, por mais diferentes (ou iguais!) que possam parecer, apresentam elementos em comum que atraem esses indivíduos. Sugerimos como hipótese que esse elemento em comum seria o aumento nos níveis de tensão-excitação - e o conseqüente divertimento - que estas atividades proporcionam. Assim, o que pretendemos com esse estudo é discutir sobre uma possível forma de interpretar, a partir da teoria de Norbert Elias e Eric Dunning, a utilização dos jogos eletrônicos como opção de lazer. A intenção é tecer algumas reflexões que colaborem para o entendimento desta prática lúdica. Tentaremos levantar, com o auxílio de questionários respondidos por indivíduos que jogam videogames, alguns motivos que levam essas pessoas a procurarem estes jogos e que tipos de experiências buscam através deles.

Porém, antes disso, achamos fundamental contextualizar a presença dos jogos eletrônicos enquanto opção de lazer na vida moderna. Muitas informações a respeito dessa atividade precisam ser levantadas para que o leitor possa ter idéia da abrangência e do crescimento do fenômeno que estamos abordando.

\section{Os JOGOS ELETRÔNICOS NA SOCIEDADE MODERNA}

Os primeiros jogos eletrônicos surgiram aproximadamente na década de 60. Desde então, devido a sua atratividade e a sua aceitação como uma ferramenta de diversão, tornaram-se cada vez mais populares. A evolução tecnológica gerada principalmente a partir do desenvolvimento dos computadores permitiu que os jogos eletrônicos se transformassem de tal maneira que muitos dos jogos criados hoje são apreciados até mesmo como obras de arte. ${ }^{2}$ Os últimos videogames produzidos atingiram níveis tecnológicos tão avançados que, devido a suas extraordinárias capacidades no processamento e à rapidez na geração de recursos gráficos, conseguem sintetizar imagens cada vez mais semelhantes às imagens reais - o que não poderia deixar de ser um atrativo.

${ }^{2}$ Para maiores informações ler: MATIAS, Alexandre. Videogame enquanto arte. Benzaitem, 2002.

Movimento, Porto Alegre, v. 14, n. 02, p. 163-183, setembro/dezembro de 2008. 
Hoje, a indústria ligada aos jogos eletrônicos e aos videogames já é considerada como a maior indústria de entretenimento no mundo, ultrapassando o faturamento da indústria do cinema:

O mercado de jogos se tornou a maior indústria de
entretenimento moderno, ela movimenta aproxima-
damente trinta bilhões de dólares [...]. A previsão
de crescimento do mercado de jogos é de $20,1 \%$ ao
ano pelos próximos cinco anos. O segmento de jogos
eletrônicos mundial cresceu tanto que ultrapassou
o faturamento do cinema [...] (RAHAL, 2006, p. 1).

Rahal (2006) afirma que, em 2001, a indústria dos jogos eletrônicos faturou US\$ 21 bilhões, quase três vezes mais que a indústria do cinema de Hollywood, que faturou US\$ 8,4 bilhões. ${ }^{3}$

Os investimentos no setor são cada vez maiores e a disputa comercial das indústrias é acirrada. Afinal, a expectativa é que o público interessado nestes produtos aumente ainda mais e que surjam novas pessoas aficionadas por este tipo de divertimento. No Brasil, apesar de existir um forte mercado para esta indústria, o desenvolvimento do setor é barrado principalmente por questões tributárias, diferente de países como Estados Unidos, Japão e Reino Unido, cujas populações representam os grandes mercados consumidores deste entretenimento (RAHAL, 2006, p. 3). O alto custo desses produtos no mercado nacional e o baixo poder aquisitivo da população restringem o acesso a essas mercadorias. No entanto, o recente interesse manifestado pelas produtoras e distribuidoras de jogos eletrônicos ao nosso país evidencia a expectativa de crescimento do mercado interno relativo a esse setor.

Outro ponto interessante a ressaltar é que, ao contrário do que se costumava pensar, jogo eletrônico não é mais diversão apenas para criança. Uma pesquisa realizada pela Associação de Consumo de Eletrônicos, dos Estados Unidos, revelou que os adultos jogam mais que os adolescentes (KOPPE, 2007). Corroborando com este

\footnotetext{
${ }^{3} \mathrm{~A}$ demonstração dessa superação da indústria dos jogos eletrônicos pode ser exemplificada com a comercialização do jogo de videogame chamado Halo 2 que vendeu 2,4 milhões de unidades à 50 dólares apenas no seu dia de lançamento, atingindo a cifra de 120 milhões de dólares em um único dia. Até então, o filme recordista de faturamento em sua estréia era Spider-man 2 que arrecadou 40 milhões de dólares.
}

Movimento, Porto Alegre, v. 14, n. 03, p. 163-183, setembro/dezembro de 2008. 
estudo, Lee (2006) afirmou que, no ano de 2006, a média de idade dos jogadores era de 33 anos. Essas estatísticas mostram que o videogame, antes considerado entretenimento apenas para crianças e adolescentes, está atingindo um público cada vez mais amplo e que é, portanto, um importante instrumento de lazer para diversas faixas etárias.

Entretanto, os jogos eletrônicos não se restringem à esfera do lazer. Muitos deles já atingiram um patamar de disputa elevado e se tornaram atividades competitivas de alto nível. Nesses casos, ficam evidentes características análogas às presentes nos esportes modernos, como a remuneração dos atletas e o incentivo governamental. $\mathrm{O}$ trecho abaixo exemplifica bem esta afirmação:

Os [jogadores] mais habilidosos são patrocinados por empresas de informática ou fabricantes de games e disputam campeonatos cujos prêmios chegam à casa dos US\$ 100 mil [...]. Na Rússia, na Inglaterra e, mais recentemente, na China, os ciberatletas são oficialmente considerados esportistas. Na Coréia do Sul, onde $70 \%$ da população possui conexão de alta velocidade à internet, o ganho anual dos melhores ciberatletas ultrapassa a marca dos US\$ 100 mil. Eles levam o assunto a sério: treinam até 12 horas por dia e vivem sob pressão, pois são constantemente observados em telões pela torcida (AZEVEDO, 2004).

O treinamento intensivo, a fadiga física e mental, o cuidado com corpo e até mesmo a espetacularização já são evidentes nestas competições de alto nível, como pode ser observado no trecho de outra reportagem:

A atmosfera que envolve um evento como o World Cyber Games lembra muito a de uma competição esportiva, de futebol ou vôlei, por exemplo. Tanto é que mesmo os ciberatletas que levaram parentes ou amigos para torcer por eles em Belo Horizonte tiveram que se submeter às regras da concentração, já que foram reservados no hotel andares exclusivos para os competidores. Além disso, alguns jogadores brasileiros já têm patrocínio, recebem salários, treinam diariamente e cuidam até mesmo de aspectos como alimentação, tudo para manter uma rotina saudável, característica de esportistas (AZEVEDO, 2005).

Movimento, Porto Alegre, v. 14, n. 02, p. 163-183, setembro/dezembro de 2008. 
Como os jogos eletrônicos estão cada vez mais presentes no cotidiano, inúmeras discussões emergem desse contexto. Surgem, por exemplo, debates sobre a influência da violência ${ }^{4}$ presente nos jogos eletrônicos na formação da criança ou sobre a falta de atividade física proporcionada pelo interesse exagerado pelo videogame, como pode ser observado na seguinte afirmação: "Outra pesquisa aponta que as crianças britânicas passam um total de dois meses por ano diante das telas de videogame - agravando a obesidade e a falta de exercícios em um país onde a saúde das crianças é um problema sério" (LEE, 2006).

Através dessas evidências, não há como desconsiderar a influência dos jogos eletrônicos na vida moderna. Diversas são as áreas de conhecimento que permitem a interpretação e a discussão de assuntos ligados a esta temática, dentre elas a Educação Física. Além dos temas levantados acima, como a violência estimulada por jogos eletrônicos ou a diminuição da prática de atividades físicas em detrimento do aumento do tempo que se passa sentado diante de uma televisão e um videogame, foi possível levantar outros focos de estudo: Costa (2005) procura refletir, em sua pesquisa, a virtualização do corpo no esporte-espetáculo e nos jogos eletrônicos e a implicação da apropriação das imagens virtuais pelas crianças; Gama (2005) discute sobre novas fronteiras epistemológicas pertinentes ao estudo do esporte $\mathrm{e}$ do movimento humano, dado o surgimento de conceitos como ciberatletas, ciberculturas e jogos digitais; Feres Neto (2001) reflete sobre o surgimento de novas vivências esportivas decorrentes do que denomina virtualização do esporte.

É importante que o profissional de Educação Física reconheça a influência dos jogos eletrônicos no comportamento das crianças. Muitos deles são repletos de histórias fantásticas, heróis, monstros, mundos exóticos e outras atrações, e não é de se admirar que as crianças - e não só elas - despertem tamanho interesse por eles.

\footnotetext{
${ }^{4}$ Em 1999, dois estudantes entraram na escola Columbine High School, nos Estados Unidos, e mataram 13 colegas a tiro. O massacre acendeu a discussão sobre a influência dos jogos eletrônicos violentos, já que os autores do assassinato teriam sido supostamente influenciados por jogos (Doom e Quake) considerados extremamente violentos. As discussões sobre casos semelhantes são constantes e em vários países muitos jogos tiveram sua comercialização proibida, como o caso do jogo Carnagedom aqui no Brasil.
}

Movimento, Porto Alegre, v. 14, n. 03, p. 163-183, setembro/dezembro de 2008. 
Algumas dessas vivências eletrônicas experimentadas pelas crianças podem, por exemplo, ser resgatadas nas aulas de Educação Física e reinterpretadas nos jogos, brincadeiras e expressões corporais. Costa (2005, p. 175) compartilha dessa opinião: “[...] a Educação Física deve comportar diversas "modalidades vivenciais" [...] e para tal deve fazer "oscilar" os processos de virtualização e atualização dos jogos/esportes, e um dos caminhos para isso é "atualizar" em experiência corporal o que é apenas vivência eletrônica”.

Neste breve tópico introdutório, buscamos retratar alguns aspectos que mostram a crescente participação dos videogames e dos jogos eletrônicos como opção de lazer. Foram citadas, também, algumas questões interessantes que estão sendo abordadas e discutidas a respeito desta prática, com o intuito de mostrar que são mais freqüentes as pesquisas relacionadas a esta temática e que existe uma preocupação e uma necessidade de ampliar o entendimento sobre ela. Todavia, não vamos abordar nenhuma das questões mencionadas acima. Como já foi dito, optamos por discutir os jogos eletrônicos a partir da teoria de Norbert Elias e Eric Dunnig. Partindo dessa idéia inicial, buscaremos discutir e traçar algumas reflexões que possam auxiliar na compreensão dos jogos eletrônicos como atividade de lazer. Passamos, então, para a discussão do assunto.

\section{A BUSCA DA EXCITAÇÃO NOS JOGOS ELETRÔNICOS}

O título deste artigo remete a uma coletânea de artigos e ensaios publicados sob a forma de livro em 1985, intitulada a Busca da Excitação. Nesta obra, os autores Norbert Elias e Eric Dunning buscaram estudar e entender as configurações presentes nas atividades de lazer.

Para estes autores, em grande parte das atividades de lazer, o ingrediente fundamental para o prazer - e o que realmente se procura nestas atividades - é uma certa excitação, em geral, agradável (ELIAS; DUNNING, 1992). Quando uma pessoa assiste a um filme, joga bola com os amigos ou se atira de uma ponte com apenas uma corda elástica presa em si mesma, ela procura experimentar emoções que, freqüentemente, não estão presentes em sua vida cotidiana, ou que, se estão presentes, não oferecem um nível elevado satisfatório

Movimento, Porto Alegre, v. 14, n. 02, p. 163-183, setembro/dezembro de 2008. 
de tensão-excitação, necessário ao próprio bem-estar do indivíduo. Ao contrário do que se costuma afirmar, os indivíduos não procuram atividades de lazer para extravasarem suas tensões ou atenuarem as cargas emocionais adquiridas após um exaustivo dia de trabalho, mas sim elevar os níveis de tensão, colocar-se em situações excitantes, vivenciar momentos que incitem ou favoreçam o desabrochar de emoções variadas. É a excitação, e não o relaxamento, que constitui o elemento principal em grande parte das atividades de lazer.

Nas sociedades modernas mais avançadas, as situações críticas sérias vividas no dia-a-dia, que levam a um aumento na tensão-excitação dos indivíduos, são muito menos freqüentes se comparado com as sociedades menos desenvolvidas (ELIAS; DUNNING, 1992). Além disso, o aumento do controle social e do autocontrole impedem que as tensões e emoções vivenciadas sejam exibidas publicamente. Demonstrações públicas exageradas de qualquer sentimento só são permitidas em espaços e ocasiões reconhecidos para tal - atividades de lazer, ocasiões de festa, enterros, comemorações, etc. Fora desses espaços, as manifestações das emoções devem ser contidas e a expressão em público de sentimentos através de gritos, choros, gestos e atitudes exacerbadas é condenada, sob a penalidade extrema de prisão ou internamento (ELIAS; DUNNING, 1992). Portanto, algumas atividades de lazer são espaços sociais onde se pode manifestar e expressar sentimentos - embora de maneira também regrada e controlada - com aceitação pública e sem punição.

A partir da leitura da obra de Elias e Dunning, emergem algumas questões para o debate neste estudo: as pessoas jogam videogames porque essa prática pode provocar um aumento agradável nos níveis de tensão-excitação? Será que nesse espaço de lazer é possível vivenciar emoções diferentes daquelas presentes nas atividades rotineiras do dia-a-dia? A expressão dos sentimentos nesses espaços é socialmente permitida?

Para colaborar com este estudo, coletamos alguns dados através de questionários respondidos por pessoas que jogam videogames. As perguntas envolviam questões como idade, profissão, atividades preferidas no lazer, há quanto tempo joga, quantas horas por semana é dedicada ao videogame, tipos de jogos eletrônicos preferidos e por

Movimento, Porto Alegre, v. 14, n. 03, p. 163-183, setembro/dezembro de 2008. 
que praticam e gostam dessa atividade nos momentos de lazer. ${ }^{5}$ No total, 31 questionários foram respondidos espontaneamente através de três fóruns de discussão na internet. Os fóruns pertenciam a sites eletrônicos especializados em assuntos relacionados a videogames e jogos eletrônicos em geral. O objetivo não era coletar uma amostra significativa de jogadores, a ponto de obter um resultado quantitativo significativo ou a ponto de generalizar o resultado obtido estendendo-o a uma população inteira. Utilizamos este questionário como uma ferramenta de pesquisa qualitativa auxiliar, com o objetivo de colaborar ou levantar questões pertinentes para a discussão do assunto. Também serviu como uma forma de perceber, mesmo que superficialmente, se os jogadores que participaram da pesquisa encaravam os jogos eletrônicos como esta pesquisa supunha.

É relevante descrever de forma breve e sucinta as características do grupo que respondeu voluntariamente ao questionário que estava disponível nos fóruns. Isso facilita o entendimento e a discussão das respostas deles enquanto jogadores de videogame. A intenção é unicamente descrever este grupo, e não realizar análises quantitativas dos dados obtidos.

A média de idade das 31 pessoas que responderam ao questionário é de 27,7 anos (desvio padrão de 5,96), variando dos 14 aos 41 anos de idade. Esta informação corrobora com a estatística apresentada inicialmente, em que a maioria dos praticantes desta atividade é adulta. Cada uma dessas pessoas jogava videogame em média 16,86 horas por semana (desvio padrão de 9,09), sendo que as respostas variaram de 5 a 40 horas semanais. Um dado interessante é que, analisando individualmente as respostas, é possível afirmar que quase todas as pessoas pesquisadas começaram a jogar videogame, ou tiverem seu primeiro contato, na infância. Talvez, a partir desta faixa etária, uns abandonaram o videogame por algum tempo e outros não, mas a longo prazo não o descartaram definitivamente como opção de lazer. A média de idade na qual eles começaram a jogar

\footnotetext{
${ }^{5}$ Para observar diretamente as perguntas e as respostas desse questionário, acessar os sites: $<$ http://www.portalxbox.com.br/e107 plugins/forum/forum viewtopic.php?74330>, <http:// forum.jogos.uol.com.br/viewtopic.php?t=1188890>, <http://gamertags.uol.com.br/ index.php?option=com_smf\&ltemid=44\&topic $=101.0>$.

Movimento, Porto Alegre, v. 14, n. 02, p. 163-183, setembro/dezembro de 2008.
} 
videogame foi 7,1 anos (desvio padrão de 2,86). Apenas uma pessoa teve seu primeiro contato mais tarde, aos 13 anos. Das opções de lazer preferidas, as mais citadas eram, obviamente, jogos eletrônicos. Outras também bastante citadas foram ir ao cinema e assistir filmes.

Não é difícil perceber que os jogos eletrônicos possuem a capacidade de incitar nos jogadores a erupção de certos tipos de emoções. Através da síntese de imagens, ${ }^{6}$ da possibilidade de interação com essas imagens utilizando um controle ${ }^{7}$ e da utilização de recursos sonoros, esses jogos podem afetar diretamente nossos sentidos. Juntamente com um enredo e com a exploração da imaginação têm-se ingredientes suficientes para a criação de situações que estimulam nossas emoções. Muitos dos jogos produzidos atualmente se assemelham aos filmes, não só pela qualidade gráfica impressionante, mas porque investem também na elaboração de roteiros e histórias profundas, no entanto, com uma vantagem radical: a possibilidade de interação. Logo, tem-se uma atividade emocionante e atrativa:

$\mathrm{Na}$ verdade, tais jogos parecem oferecer àqueles que os manipulam a possibilidade de se inserirem em uma "realidade" mais rica de emoção do que aquela que poderiam encontrar em suas próprias experiências, particularmente quando estas não correspondem às suas potencialidades criadoras. Enquanto a realidade é muitas vezes tomada como ilegítima, no jogo o que importa é a fantasia vivida eletronicamente. Assim sendo, os videojogos, principalmente os que sugerem violência, possivelmente funcionam como uma espécie de catarse para a angústia, o sonho, e também para a inclinação que jovens e crianças têm pelo perigo, pelo desafio competitivo, pela experiência (CABRAL, 1997).

É possível encontrar nas respostas dos questionários comentários que demonstram a observação acima. Algumas dessas respostas sugerem que os jogos eletrônicos têm, além da capacidade de despertar

\footnotetext{
6 "As imagens computadorizadas recebem a denominação de imagens de síntese, por serem obtidas pela reunião de matrizes matemáticas diagramadas em equações algébricas diferenciais. Logo, elas derivam de operações lógicas desencadeadas por metalinguagens numéricas condensadas em programas" (LYOTARD, 2000 apud GAMA, 2005, p. 170).

7 Joystick nos videogames e até mesmo mouse e teclado no caso do computador.
}

Movimento, Porto Alegre, v. 14, n. 03, p. 163-183, setembro/dezembro de 2008. 
emoções, a possibilidade de oferecer aos jogadores emoções diferentes daquelas vividas cotidianamente. Medo, raiva, alegria, euforia, tensão, prazer e felicidade foram algumas das palavras citadas nos questionários.

Analisando nosso cotidiano, é fácil observar que as situações que vivenciamos são extremamente rotineiras. Obrigações familiares, cuidados com higiene, satisfação das necessidades vitais e principalmente atividades laboriosas (que quase sempre demandam maior tempo) são exemplos dessas atividades rotineiras, das quais, em situações socialmente tidas como normais, nenhum indivíduo está livre. São atividades rotineiras que devem ser cumpridas, mas que não trazem níveis satisfatórios de excitação ou raramente apresentam níveis elevados de tensão, ou, ainda, a expressão dessa tensão não é socialmente permitida, ou a tensão em si é desagradável. O tempo de lazer acaba sendo o momento em que os indivíduos podem escapar da rotina e buscar uma elevação dos níveis de tensão que se apresentam diminuídos ou contidos nas atividades rotineiras. Assim, os desportos e muitas das atividades de lazer "[...] destinam-se a movimentar, a estimular as emoções, a evocar tensões sob a forma de uma excitação controlada e bem equilibrada, sem riscos e tensões habitualmente relacionadas com o excitamento de outras situações da vida" (ELIAS; DUNNING, 1992, p. 79).

Essa visão é compartilhada pelos jogadores que participaram do fórum, pois traziam comentários que indicavam que os jogos eletrônicos serviam como um entretenimento relaxante, uma forma de distração, um meio de escapar da realidade. Algumas destas frases foram listadas abaixo, e cada uma pertence a uma pessoa diferente. São trechos das respostas obtidas na pergunta "Por que você gosta de jogos eletrônicos?". Os grifos são de minha autoria:

Experimentar situações que eu nunca poderia em minha vida e relaxar enquanto isso.

Acho que é o melhor meio para fugir dos problemas, basta sentar, pegar o controle e relachar [sic], esquecendo de tudo o que você passou no dia e etc.

Pela possibilidade de divertimento e "fuga" (no bom sentido) que eles proporcionam.

Movimento, Porto Alegre, v. 14, n. 02, p. 163-183, setembro/dezembro de 2008. 
Pra mim é uma forma de me desligar dos problemas e dores de cabeça do dia-a-dia. Relaxo muito jogando video-game. Outro fator é a diversão proporcionada.

Porque é ótimo pra esquecer os problemas, sejam eles quais forem.

Pra relaxar, esquecer o stress do dia a dia, ou algo que me aborreça. Enfim, pra abstrair [...]

Esquecer do mundo faz bem.

Sair um pouco da real às vezes faz bem. Você acaba vivendo situações que não viveria no seu cotidiano.

Esses são apenas alguns exemplos, porém, foram muitas as respostas que traziam esta idéia de fuga do cotidiano. Comentários sobre se desligar, esquecer e fugir dos problemas estavam presentes em muitas outras respostas. Seja de maneira explícita, ou até mesmo implícita, a maioria desses indivíduos defendiam que jogavam videogame porque podiam, através dele, se afastar das atividades rotineiras, dos assuntos desagradáveis, das obrigações familiares e das preocupações no trabalho. Deduz-se que, para eles, o ato de jogar videogame exige certa concentração e que, principalmente por este motivo, acaba desviando toda a atenção da realidade a sua volta para o jogo em si. Dessa forma, afasta momentaneamente qualquer pensamento que aflige ou perturba o indivíduo, substituindoos por pensamentos que o indivíduo sabe que não são reais e que sumirão ao fim do divertimento. Daí o surgimento de muitas falas que afirmam essa opinião.

Semelhante a outras atividades de lazer, jogar videogame realmente pressupõe certo nível de atenção e concentração (já que exige habilidade e coordenação motora fina) e isso pode levar os indivíduos a "esquecerem dos problemas". Entretanto, este fato não pode ser entendido como o único ou o principal fator, como os próprios jogadores definiram que os levariam a realizar tal atividade. Se assim fosse, talvez as crianças não se interessassem por estas atividades, já que não enfrentam responsabilidades, preocupações e problemas exclusivos do mundo dos adultos. "A fuga da realidade" pode ser uma conseqüência, mas não o fim em si desta prática lúdica.

Movimento, Porto Alegre, v. 14, n. 03, p. 163-183, setembro/dezembro de 2008. 
Algumas opiniões dos jogadores apontam para o fato de que os jogos eletrônicos atraem porque podem oferecer experiências diferentes em ambientes e situações diferentes, despertando a imaginação e a fantasia:

[...] o que me atrai principalmente nos jogos é a possibilidade de explorar um mundo novo, em que você consiga "dobrar" as regras e experienciar algo totalmente original sem sair da sua casa. Seria uma espécie de livro, contando com uma história complexa e cativante, somado à apresentação cinematográfica, repleta de efeitos visuais e sonoros, e embrulhada na interatividade que você teria com isso, muito maior do que você tem com um filme ou com um livro.

[...] distração, me leva a lugares onde nunca posso estar (guerras, cruzadas, reinos medievais).

Uma oportunidade de "mergulhar" em locais/mundos/situações que seriam impossíveis na vida real. Sem contar que acaba sendo uma terapia.

[...] games são uma forma de entrar em contato com realidades diferentes da minha.

Estes jogadores estão falando dos jogos eletrônicos modernos e, se observarmos os jogos mais antigos, podemos observar que essa atração pela riqueza fantasiosa dos jogos não pode ser tão determinante assim. Se observarmos o jogo Pac-man, ${ }^{8}$ podemos concluir que não era o seu ambiente composto de pontos, retas, círculos e pouco mais de 16 cores que o tornava atrativo na época, mas provavelmente pelo divertimento provocado principalmente pelo aumento dos níveis de tensão-excitação decorrentes da participação interativa no jogo. Nos jogos eletrônicos modernos a qualidade dos gráficos, dos efeitos sonoros, da música e das histórias são indiscutivelmente superiores, no entanto, assim como nos jogos mais antigos,

\footnotetext{
${ }^{8}$ Pac-man é considerado um clássico da história dos video games. Produzido para o console Atari 2600 no início dos anos 80 , tornou-se um jogo bastante popular. A mecânica do jogo funcionava da seguinte forma: o jogador era representado por uma cabeça redonda com uma boca que se abre e fecha, posicionado dentro de um labirinto repleto de pastilhas. Dentro do labirinto existiam quatro fantasmas que o perseguiam. O objetivo era comer todas as pastilhas sem deixar ser alcançado pelos fantasmas.
}

Vovimento, Porto Alegre, v. 14, n. 02, p. 163-183, setembro/dezembro de 2008. 
as empresas criadoras destes jogos buscam, através das mais diferentes possibilidades e estilos de jogos, oferecer impreterivelmente cenas e situações propícias a elevação dos níveis de excitação dos jogadores. Talvez a possibilidade de experimentar situações excitantes e elevar os níveis de tensão seja um componente importante, senão o principal dessa prática de lazer.

Muitos dos sentimentos suscitados pelas atividades de lazer têm origem em sentimentos presentes no cotidiano. O que difere fundamentalmente é o fator risco. No lazer, é possível vivenciar diversas situações que transmitem sensação de risco, perigo ou medo, sem causar diretamente risco à vida dos participantes. É como o sentimento de medo despertado em um filme de terror. Elias (1992) enquadra esta peculiaridade das atividades do lazer sob o conceito de "atividades miméticas", que são atividades que:

\begin{abstract}
[...] despertam emoções de um tipo específico que estão intimamente relacionadas de uma forma específica, diferente, com aquelas que as pessoas experimentam no decurso da sua vida ordinária de não lazer (ELIAS; DUNNING, 1992, p. 183).
\end{abstract}

Ainda, segundo ele, estas atividades do tipo mimético indicam que:

[...] os sentimentos dinamizados numa situação imaginária de uma atividade humana de lazer têm afinidades com os que são desencadeados em situações reais da vida (ELIAS; DUNNING, 1992, p. 71).

Nas atividades miméticas é possível vivenciar situações semelhantes às reais e experimentar tensões-excitações verdadeiras também semelhantes àquelas enfrentadas em situações reais - sem, entretanto, atentar contra a própria vida.

Nos jogos eletrônicos, muitas dessas características citadas também estão presentes. Vejamos algumas falas dos jogadores (os grifos são de minha autoria):

Emoção de infringir as leis do mundo real sabendo que não irei ferir ninguém realmente [...]

Acho uma ótima diversão, pois alivia das pressões do dia a dia sem nos expor a desgaste algum e a nenhum perigo.

Movimento, Porto Alegre, v. 14, n. 03, p. 163-183, setembro/dezembro de 2008. 


\begin{abstract}
E ainda acho um meio maravilhoso para que possamos fazer coisas que nunca faríamos em nossa vida real.

Uma forma de ser mal[sic] sem ser, de ser o melhor também sem ser, apenas pelo fato de sermos todos crianças!!!
Jogar é fazer algo que você nunca vai poder, ou mesmo tomar uma atitude diferente da que você tomaria na vida real por pura diversão, NUNCA confundindo o mundo real do virtual.
É uma forma de "entrar" numa outra realidade e fazer coisas que jamais poderia fazer na vida real, além de fazer-me esquecer os problemas por alguns instantes;
\end{abstract}

Como já foi dito, nos jogos eletrônicos, assim como em outras atividades miméticas, os jogadores podem vivenciar situações e, conseqüentemente, emoções decorrentes delas, semelhantes às reais, sem que isso lhe cause qualquer dano real. O jogador pode incorporar o herói e experimentar a emoção de sair enfrentando monstros e dragões; pode ser um soldado e viver a tensão de uma guerra; pode ser o técnico, o capitão e o artilheiro do time e se frustrar com o gol sofrido no último minuto; pode sentir o medo ao comandar sua legião à batalha final ou a excitação de arriscar toda sua fortuna num jogo de cartas. Nestes exemplos, cada uma dessas experiências eletrônicas irá propiciar ao jogador o despertar de emoções de tipos específicos e graus variados.

Por mais que essas emoções despertadas de forma mimética sejam totalmente distintas das emoções que emanam de situações reais (e isso não pode, por enquanto, ser cientificamente averiguado), e que os níveis de intensidade das últimas sejam muito superiores das primeiras, não pode ser negado que há um estímulo cerebral que provavelmente desencadeará mudanças, em maior ou menor intensidade, nos níveis de tensão do indivíduo.

Muitos jogadores mencionaram a possibilidade de tomar uma decisão ou fazer algo dentro do jogo que não poderia ser feito em situações reais. Esta é uma característica bastante atrativa dos jogos

Movimento, Porto Alegre, v. 14, n. 02, p. 163-183, setembro/dezembro de 2008. 
eletrônicos. Possibilita aos jogadores experimentarem - de forma mimética - situações socialmente proibidas ou, até mesmo, situações impossíveis de acontecerem na vida real. Por isso, os jogos eletrônicos e a maioria das atividades de lazer acabam gerando emoções e sentimentos que, definitivamente, não são facilmente despertados com as atividades presentes no cotidiano, principalmente por que muitos destes sentimentos estão relacionados a situações que não são permitidas pela sociedade e nem pelos próprios indivíduos. Assim, num jogo onde o protagonista rouba um carro e foge freneticamente da polícia, o jogador pode experimentar de forma mimética a emoção daquela fuga, sabendo que, ao contrário da realidade, qualquer insucesso não iria lhe custar a liberdade ou até mesmo a vida. Além disso, o faz com respaldo social e da própria consciência, e não irá, de forma alguma, se culpar por fazer algo que não é socialmente permitido.

\section{CONSIDERAÇÕES FINAIS}

A idéia que tentamos desenvolver nessa pesquisa foi que os jogos eletrônicos são como muitas outras atividades de lazer, nas quais a busca da excitação é o principal atrativo e a fonte do prazer. E essa idéia foi bem exemplificada pela situação descrita no começo deste artigo, sobre as diferentes atividades realizadas pelo pai e seu filho. Talvez, apesar das inúmeras diferenças, pai e filho queriam exatamente a mesma coisa: apenas brincar de "polícia pega ladrão". Se pensarmos por que as crianças brincam e se interessam pelas duas atividades citadas no tópico introdutório, enquanto os adultos dificilmente convidariam seus amigos para brincarem de escondeesconde, podemos compreender, em partes, esta rápida ascensão dos jogos eletrônicos como divertimento.

A opção pelos jogos eletrônicos como opção de lazer conta com um forte aliado a seu favor: o comodismo. Afinal, o deslocamento até um espaço de lazer, seja ele uma praça, museu, clube ou cinema, pode ser muito demorado, desinteressante ou até mesmo estressante, sem contar com o medo e a insegurança gerados pela violência urbana. Além disso, a participação de jogos com outras

Movimento, Porto Alegre, v. 14, n. 03, p. 163-183, setembro/dezembro de 2008. 
pessoas via internet é cada vez mais comum, ${ }^{9}$ o que dispensa a dependência em relação a amigos ou grupos de amigos específicos que seriam indispensáveis à realização das muitas outras atividades de lazer. Esse fato provoca modificações nos hábitos e comportamentos das pessoas, contribuindo para o esvaziamento da esfera pública e pela restrição das práticas de lazer aos ambientes privados e familiares.

Independente de qualquer julgamento em relação aos benefícios ou malefícios dos jogos eletrônicos, em comparação a outras atividades de lazer, enfatizamos a importância e a necessidade de estudos direcionados para o entendimento desta atividade. Queiramos ou não, é uma opção de lazer que adquire cada vez mais novos adeptos, e, quem sabe, não o faz à custa do tempo dedicado a outras práticas de lazer? Seriam as atividades físicas e a própria Educação Física vítimas dessa expansão?

Esta é uma questão polêmica para os pais, que enfrentam um verdadeiro dilema quando se vêem pressionados pelos filhos para comprar um videogame. Por um lado, sentem-se seguros por manter o filho em casa, longe dos perigos das ruas, mas, por outro, acabam se questionando se o desenvolvimento do filho não estaria sendo prejudicado. Neste ponto, não há como definir até onde seria saudável ou não jogar videogame. Mas é uma preocupação pertinente, já que o excesso dessas práticas, cuja demasia em si já não é benéfica, acaba impedindo a realização de outras práticas que seriam fundamentais para o desenvolvimento motor, cognitivo e social da criança. Além do bom senso para reconhecer exageros quanto ao tempo despendido com esta brincadeira, os pais deveriam se preocupar em oferecer aos filhos outras atividades de lazer que sejam tão ou mais interessantes que os próprios jogos eletrônicos. Oportunizar às crianças outras atividades que também elevem os níveis de tensão-excitação parece ser um ponto fundamental, pois parece ser justamente essa

\footnotetext{
${ }^{9}$ Os jogos eletrônicos têm explorado muito a possibilidade de interação com outros jogadores através da internet. Com os últimos videogames lançados no mercado, por exemplo, é muito fácil e rápido se conectar a internet, bastando somente ligar o videogame e apertar alguns botões. A partir daí é possível jogar o mesmo jogo com pessoas espalhadas em vários cantos do mundo.

Vovimento, Porto Alegre, v. 14, n. 02, p. 163-183, setembro/dezembro de 2008.
} 
característica - de acordo com tudo que tentamos discutir neste texto - que os torna tão atraentes. De outro modo, entendemos que privar as crianças desta opção de lazer, ou negar sua existência, também não parece ser a atitude mais sensata, afinal, muitos dos jogos eletrônicos possuem aspectos positivos como, por exemplo, oportunizar vivências miméticas. Assim, as crianças podem experimentar e vivenciar situações que causam emoções sem ter que se submeter a riscos reais, experiência que estimularia o sistema nervoso central (KANITZ, 2005). ${ }^{10}$

Sendo considerado a maior indústria do entretenimento moderno, os jogos eletrônicos não estão, absolutamente, imunes aos interesses da indústria cultural. Como no ramo da música, do cinema e das diversões em geral, os jogos eletrônicos estão inseridos numa lógica capitalista dominante e são criados com o objetivo de obter o maior retorno financeiro possível. Assim, muitas produtoras apelam demasiadamente para a violência ou para questões polêmicas em seus títulos e muitos dos jogos produzidos não passam de reproduções caça-níquel que seguem receitas que são garantias de sucesso: explosão e sangue. Por isso, além de bom senso para impor limites de tempo à brincadeira, os pais devem ser cuidadosos e selecionar $\mathrm{o}$ que o filho poderia jogar.

Um último ponto a ser tocado, relaciona-se à associação da interatividade ao movimento corporal. Da última geração de videogames lançados no mercado, o que obteve mais sucesso em vendas foi um videogame que buscou apresentar uma forma diferenciada de se jogar, muito diferente daquelas formas tradicionais, nas quais o indivíduo senta diante da televisão e ali fica horas, estático. Transformaram o controle (que parecia muito complexo para aqueles que nunca tinham se interessado por jogos) em um objeto mais simples, similar a um controle remoto, porém totalmente sensível ao movimento. Com isso, os jogadores ganharam a possibilidade de simular diretamente com seu próprio corpo a ação que desejavam

\footnotetext{
${ }^{10}$ Kanitz defende em seu artigo a importância de estimular o cérebro da criança a fim de impedir a regressão sináptica, sendo os jogos eletrônicos uma ferramenta excelente para auxiliar nesta tarefa já que podem enganar o cérebro ao simular ambientes hostis e perigosos.

Movimento, Porto Alegre, v. 14, n. 03, p. 163-183, setembro/dezembro de 2008.
} 
que o personagem fizesse no jogo. Assim, em um jogo de tênis, não é mais o apertar de um botão que vai rebater a bolinha, mas sim o respectivo movimento executado na vida real, simulando o rebater da bolinha. Um golpe de espada num jogo medieval não é desferido pelo botão, pois agora o jogador segura a própria espada (o controle) em suas mãos e os movimentos executados pelos seus braços é que determinarão a ação no jogo. Sem dúvida estes avanços tecnológicos, que parecem pequenos ou lentos demais a olhares despercebidos, poderão influenciar diretamente a prática esportiva e a Educação Física. Uma ferramenta aliada, quem sabe?

São algumas questões que, apesar de complexas e até mesmo atemporais para o ponto de vista de alguns, podem e deveriam ser discutidas principalmente pelos profissionais da Educação Física e do lazer, afinal, parece que o futuro dos jogos está cada vez mais relacionado ao movimento humano.

Movimento, Porto Alegre, v. 14, n. 02, p. 163-183, setembro/dezembro de 2008. 


\begin{abstract}
Electronic Games and the Search of the Excitement

Abstract: In the branch of the entertainment, the industry of the electronic games was the one that more grew in the last decade, having attracted attention of researchers of diverse areas, amongst them the Physical Education. Why the electronic games have arouse so great interest as option of leisure for children, young and adults? In this study we intend to argue on a possible form to interpret, from the theory of Norbert Elias and Eric Dunning, the electronic games as leisure option, using as tool auxiliary questionnaires answered for individuals that play videogames. The intention is to weave some reflections that collaborate for the agreement of this practical playful.
\end{abstract}

Keywords: Video games. Leisure activities. Emotions. Eletronic industry.

\begin{abstract}
Juegos electrónicos y la búsqueda del entusiasmo

Resumen: En el rama de la diversión, la industria de los juegos electrónicos era la que más crecieron en la década pasada, atrayendo la atención de los investigadores de áreas diversas, entre ellas la educación física. ¿Por qué los juegos electrónicos tienen despertar interés tan grande como opción del ocio para los niños, los jóvenes y los adultos? En este estudio nos preponemos discutir en una forma posible para interpretar, de la teoría de Norbert Elias y de Eric Dunning, los juegos electrónicos como opción del ocio, usando como cuestionarios auxiliares de la herramienta contestados para los individuos que juegan juegos de video. La intención es tejer algunas reflexiones que colaboren para el acuerdo de este juguetón práctico.

Palabras clave: Juegos de vídeo. Actividades recreativas. Emociones. Industria electrónica.
\end{abstract}

\title{
REFERÊNCIAS
}

ASSIS, Diego; MATIAS, Alexandra. Próxima Jogada. Gamenet, São Paulo, 2004. Disponível em: <http://www.gamenetpr.com.br/gamenet.html>. Acesso em: 24/jun/ 2007.

Movimento, Porto Alegre, v. 14, n. 03, p. 163-183, setembro/dezembro de 2008. 
AZEVEDO, Théo. World Cyber Games, a olimpíada dos jogos eletrônicos. Uol Jogos, São Paulo, 2005. Disponível em: <http://jogos.uol.com.br/reportagens/ultnot/ ult2240u52.jhtm>. Acesso em: 30 abr 2007.

Jogar via internet vira profissão para aficionados. Folha Online, São Paulo, 2004. Disponível em: <http://jogos.uol.com.br/reportagens/ultnot/ ult2240u52.jhtm>. Acesso em: 30 abr 2007.

BRESCIANI, Antonio Alex. A breve e lucrativa história de consolidação dos jogos. Mercado B. São Paulo, 2003. Disponível em: <http://www.benzaiten.com.br/ artigo/consolidacao_jogos.htm>. Acesso em: 30 abr 2007.

CABRAL, Fátima. Jogos eletrônicos: técnica ilusionista ou emancipadora? Benzaitem, 2007. Disponível em: <http://www.benzaiten.com.br/artigo/ilusionista _emancipadora.htm>. Acesso em: 2 maio 2007.

COSTA, Alan Queiroz. Mídia e jogos: do virtual para uma experiência corporal educativa. Revista Brasileira de Ciências do Esporte, Campinas, v. 27. n. 2, p. 165-178, jan. 2005.

ELIAS, Norbert; DUNNING, Eric. A busca da excitação. Lisboa: Difel, 1992.

FERES NETO, Alfredo. A virtualização do esporte e suas novas vivências eletrônicas. 2001. 117 fls. Tese (Doutorado em Educação) - Faculdade de Educação, Universidade Estadual de Campinas, Campinas, 2001.

GAMA, Dirceu Ribeiro Nogueira. Ciberatletas, cibercultura e jogos digitais. Considerações epistemológicas. Revista Brasileira de Ciências do Esporte, Campinas, v. 26, n. 2, p. 163-177, jan. 2005.

KANITZ, Stephen. A favor dos games. Revista Veja, v. 38 , n. 41 , p. 22, 12/out/ 2005. Disponível em:<www.kanitz.com.br>. Acesso em: 20 abr 2007

KOPPE, Jennifer. Coisa de gente grande. Gazeta do Povo, Curitiba, 6 maio 2007. Caderno ViverBem.

LEE, Reuters Gaetan. Exposição em Londres questiona se videogames seriam "benção" ou "maldição". FolhaOnline, São Paulo, 2006. Disponível em: <http:// www1.folha.uol.com.br/folha/informatica/ult124u20820.shtml>. Acesso em: 28 abr 2007.

MATIAS, Alexandre. Videogame enquanto arte. In: Benzaitem, 2002. Disponível em: <http://www.benzaiten.com.br/artigo/videogame_enquanto_arte.htm>. Acesso em: 24 v. 1 jun 2007.

RAHAL, Fernando de Castro. Desenvolvimento de jogos eletrônicos. 2006. 32 fls. Trabalho de conclusão de curso (Bacharel em Engenharia da Computação). São Paulo, Centro Universitário Assunção, 2006.

Recebido em: 21/08/2007 Aprovado em: 12/05/2008

Movimento, Porto Alegre, v. 14, n. 02, p. 163-183, setembro/dezembro de 2008. 